\title{
QUEEN'S
UNIVERSITY
BELFAST
}

\section{Achieving rational design of alloy catalysts using a descriptor based on a quantitative structure-energy equation}

Ding, Y., Xu, Y., Mao, Y., Wang, Z., \& Hu, P. (2020). Achieving rational design of alloy catalysts using a descriptor based on a quantitative structure-energy equation. Chemical Communications, 56(21), 3214-3217. https://doi.org/10.1039/c9cc09251j

Published in:

Chemical Communications

Document Version:

Peer reviewed version

Queen's University Belfast - Research Portal:

Link to publication record in Queen's University Belfast Research Portal

\section{General rights}

Copyright for the publications made accessible via the Queen's University Belfast Research Portal is retained by the author(s) and / or other copyright owners and it is a condition of accessing these publications that users recognise and abide by the legal requirements associated with these rights.

Take down policy

The Research Portal is Queen's institutional repository that provides access to Queen's research output. Every effort has been made to ensure that content in the Research Portal does not infringe any person's rights, or applicable UK laws. If you discover content in the Research Portal that you believe breaches copyright or violates any law, please contact openaccess@qub.ac.uk. 


\title{
Achieving Rational Design of Alloy Catalysts Using a Descriptor Based on a Quantitative Structure-energy Equation
}

\author{
Yunxuan Ding, ${ }^{a}$ Yarong $\mathrm{Xu},{ }^{\mathrm{a}, \mathrm{b}}$ Yu Mao, ${ }^{\mathrm{a}}$ Ziyun Wang ${ }^{\mathrm{a}}$ and P. Hu*a
}

An approach to rationally design optimal alloy catalysts is established using nitric oxide (NO) oxidation as an example. We introduce a quantitative structure-energy equation to predict the chemisorption energies of adsorbates on alloy catalysts. The structure-energy descriptor is used to rationally design Pt-based and Ni-based alloy catalysts for NO oxidation. Full first principles calculations with kinetic simulations demonstrate that these designed catalysts possess much better catalytic performances than the traditional catalysts.

In recent years, some fundamental breakthroughs, e.g. the Brønsted-Evans-Polanyi (BEP) relation1-5 and linear scaling6-8, have been made to describe the chemisorption energy and catalytic activity. The linear scaling6-8 can be used to estimate the chemisorption energies of a series of similar surface species. Based on the BEP relation1-5, the reaction barriers can be correlated with the reaction energy. With the BEP relations and the linear scaling from a catalytic system, the activity against the chemisorption energy (or energies) of a key species (or several species) can be constructed typically displaying a volcano curve, in which the chemisorption energy can be considered as an energy descriptor to depict the overall rate of the reaction9, 10. From the volcano curve of the specific reaction, the optimal chemisorption energy or energies on the best catalyst for the particular reaction can be readily obtained.

Nørskov and co-workers 11, 12 pioneered a new means of catalyst development by screening a large amount of catalysts from a database to find new catalysts with the chemisorption energies close to one that is at the peak of the volcano curve. Several groups12-14 reported that the energy windows can be used to search for the optimal catalysts. It was pointed out in our work13 that the lower and upper boundaries of the energy window can be determined by considering the adsorption and desorption as the rate-determining steps, respectively, using which optimal catalysts may be searched. With the development of machine learning, several optimal catalysts and a variety of facets with active sites were also successfully identified15-19. However, most of the current strategies for finding new catalysts rely on the pre-compiled database or existing structures. Moreover, a huge amount of calculations is also needed on the purpose of training.

It is clear that an approach of rational catalyst design is highly desirable. Andersen et al. identified several descriptors by the sure independence screening and sparsifying operator (SISSO) method and successfully screened some materials and the active site20. However, it is important to unravel the relationship between the catalyst surface structure and adsorption energy. If the chemisorption energies for reactants on surface structures could be predicted, it would be straightforward to calculate the catalytic activity and therefore make it possible to inversely design the ideal catalysts for the reaction.

To this end, Nørskov and co-workers21, 22 found that the chemisorption energies of adsorbates are correlated to the $d$-band centers of the transition-metal surfaces on which the adsorbates are on, the so-called d-band center model. Sautet and co-workers7, 23, 24 made a breakthrough by proposing the concept of a generalized coordination number with a simple formula to predict the chemisorption energies on pure metal nanoparticles 23 and surfaces7, 
and used this formula to find out a novel catalyst for the oxygen reduction reaction (ORR)24. After investigating the trend of adsorption energies for a series of Pt-based alloys (Pt/Re, $\mathrm{Pt} / \mathrm{Os}, \mathrm{Pt} / \mathrm{Ir}, \mathrm{Pt} / \mathrm{Pd}$ ), in a previous work25 our group developed the bonding contribution equation (BCE) (Eq. S2) and used the equation to predict chemisorption properties on alloys. Despite this progress, some problems still remain. As only five elements were used in the work, and four of them were in the same period, these elements have similar structure properties. This might make this method not be of general use for other metals.

In this work, a general formula, named the quantitative structure-energy equation (QSEE), which predicts the chemisorption energy on alloy catalyst surfaces, is derived with three components, the contribution factor, the geometric effect and the electronic effect. Furthermore, NO oxidation is used as an example to illustrate a framework of rational catalyst design for several reasons: Firstly, the oxidation of NO to NO2 plays a key role in several NOx abatement technologies26-28, including NOx storage-reduction (NSR)29-31, continuously regenerating trap (CRT)32, 33 and selective catalytic reduction (SCR) of NOx34, 35. In all these technologies, NO2 is either an intermediate species or can enhance the reaction rate36, 37. Secondly, it is a simple reaction with all the common surface reactions:
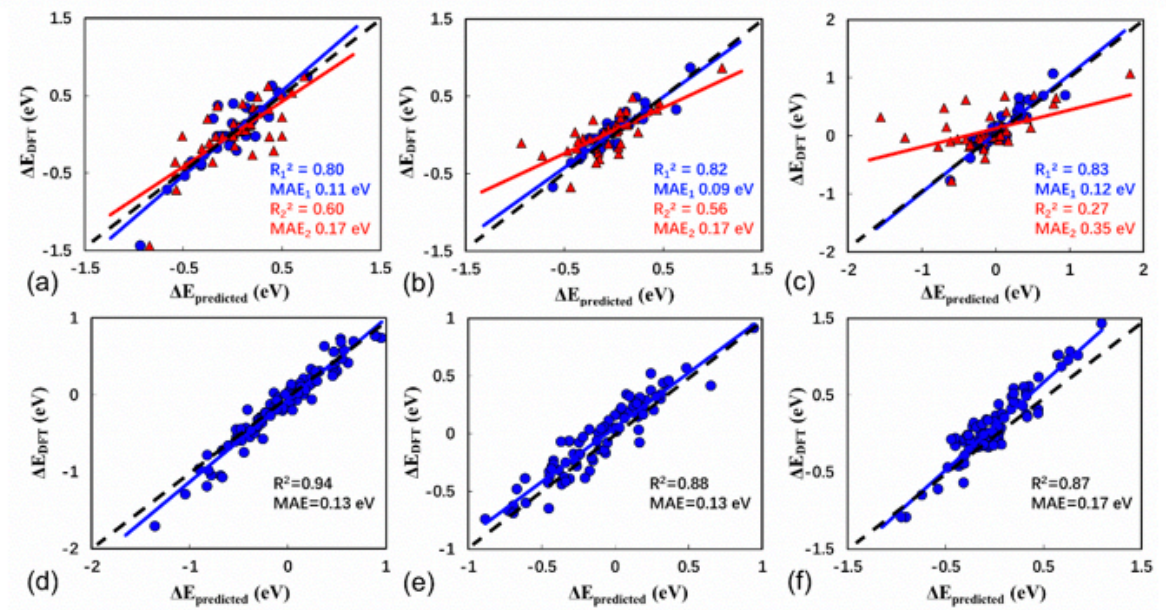

Fig. 1 Comparisons between the predicted relative chemisorption energies from the QSEE and those from DFT calculations. (a) The chemisorption energies of an oxygen

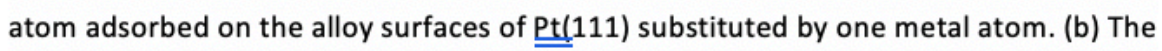

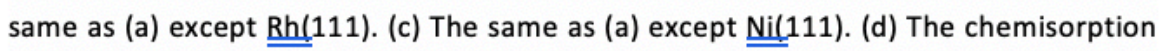
energies of an oxygen atom adsorbed on the randomly generated alloy surfaces of Pt(111) substituted by two metal atoms. (e) The same as (d) except Rh(111). (f) The

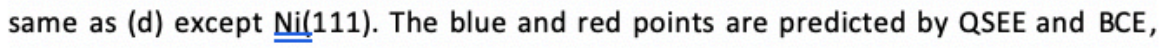
respectively.

dissociative adsorption of reactants, surface reaction and product desorption. Thus, a successful strategy of rational catalyst design for NO oxidation may be of general use for catalytic systems in heterogeneous catalysis.

Firstly, we calculated the relative adsorption energies of $\mathrm{O}$ on three groups of alloys using $\mathrm{Ni}, \mathrm{Rh}$ and $\mathrm{Pt}$ as base metals, respectively, with twelve transition metals from 3$\mathrm{d}(\mathrm{Co}, \mathrm{Ni}$, and $\mathrm{Cu}), 4-\mathrm{d}(\mathrm{Ru}, \mathrm{Rh}, \mathrm{Pd}$, and $\mathrm{Ag}$ ) and 5-d (Re, Os, Ir, Pt and $\mathrm{Au}$ ) periods as solutes by utilizing the BCE. It is found that the results from the BCE are not adequate for these systems, as shown in Fig. 1(a), (b) and (c) in red points: Compared to DFT calculation values, the errors of the predictions from the equation are too large to be of use. Therefore, a more general equation accounting for a wider range of metals is needed. 
In this work, we propose a QSEE to predict adsorption energies, in which the formula is shown as follows:

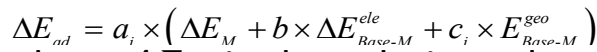

where $\Delta E_{M}$ is the relative adsorption energy of metal $M$ (Eq. S1), $E_{\text {Base-M }}^{\text {geo }}$ refers to the geometric effect obtained from the change of the adsorption energy with the introduction of a solute $M$, and $\Delta E_{\text {Base } M}^{\text {ele }}$ is the electronic effect calculated from the difference between the bonding energies of an base atom in the base and a solute metal atom in the base. $b$ and $c_{i}$ are the coefficients for the electronic and geometric effects, respectively. Coefficient $a_{i}$ represents the contribution factor for substitution type $i$ defined in our previous work ${ }^{25}$ (for detailed derivations see Supporting Information (SI)). In this equation, the geometric and electronic effects are introduced to improve the accuracy of the prediction (the rational will be explained late).

The results from the QSEE (Eq. 1) are shown in Fig. 1 (a) - (c) (blue points), in which the red points are predicted by the BCE for comparison. Two interesting features are evident in the figures: (i) The QSEE has much better performance for predicting the relative adsorption energies than those from the BCE. (ii) Even for Ni-based alloys, for which the BCE did not work at all, the QSEE shows a good correlation between the predicted relative adsorption energies from the equation and the DFT calculation results. It is worth mentioning that upon comparison of the QSEE to the BCE, the QSEE only has two additional parameters, which can be readily obtained from clean pure surface calculations.

We also randomly chose any two different transition metals to be the solute metals to check the feasibility of the equation for multi-component alloys, in which 90 alloys were generated for each base metal. As illustrated in Fig. 1(d) - (f), the correlations $\left(R^{2}\right)$ between the predicted data from the QSEE with the DFT calculation results for Pt, $\mathrm{Rh}$ and $\mathrm{Ni}$ based alloys are $0.94,0.88$ and 0.87 , respectively. It is worth emphasizing that the base metals in this work include a transition metal from $3 d, 4 d$ and $5 d$ periods and the solute metals cover a wide range of metals ( 12 metals including both active metals such as $\mathrm{Re}$ and inert metals such as $\mathrm{Au}$ in the periodic table, and the total amount of possible alloys for each base metal is 429,981,696 $\left(12^{8}\right)$ ), indicating a completeness of the equation to cover a variety of alloys. Therefore, we expect that the QSEE may work for many alloys for O adsorption.

To double-check the generality of the QSEE, nitric oxide (NO) was chosen to be another adsorbate. Using the same method for the oxygen adsorption (see more details in the $\mathbf{S I}$ ), the relative adsorption energies of NO on these three base alloys were calculated and the results are shown in Fig. 2, which demonstrates again a good accuracy of the equation: The correlations $\left(R^{2}\right)$ of NO between the predicted data from the QSEE and the DFT calculations on Pt, Rh and Ni based alloys are 0.91, 0.92 and 0.94, respectively. In addition, we also tested a more common surface species, atomic carbon (C), on Pt-based alloys, from which the chemisorption energies of many surface species, such as $\mathrm{CH}, \mathrm{CH}_{2}$ and $\mathrm{CH}_{3}$, can be obtained from the linear scaling relations. Again, a good correlation between the predicted data from the QSEE and the DFT calculations is achieved (Fig. S4). It is worth emphasizing that the surface species considered above $(\mathrm{O}, \mathrm{NO}$ and $\mathrm{C})$ arguably represent the most common intermediates in heterogeneous catalysis and additionally they adsorb on the different surface sites, illustrating a wide range of applications of the equation. The good accuracies of the QSEE from these systems demonstrate that the QSEE may be of general use.

The rational of including the geometric and electronic effects in the QSEE can be briefly explained using the following example (see more details in the $\mathrm{SI}$ ), in which the $\mathrm{O}$ chemisorption is considered. With the addition of a solute atom in the surface because of the different lattice constant of solute metal from that of the base metal, the surface structure will be compressed 

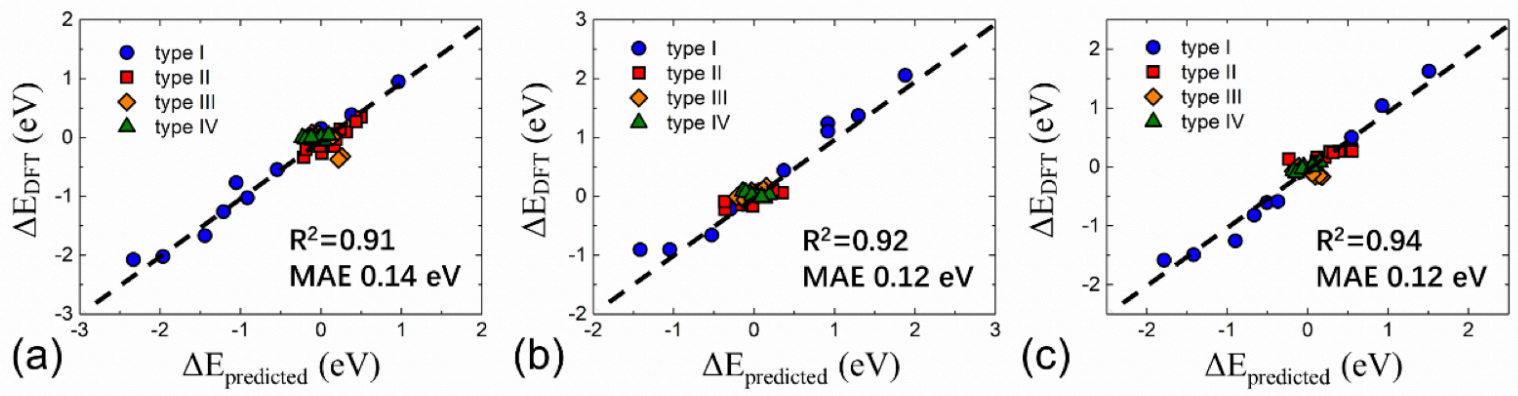

Fig. 2 Comparisons between the predicted relative chemisorption energies from the QSEE and those from DFT calculations. The results for NO adsorbed on the alloy surfaces of (a) Pt(111), (b) $\mathrm{Rh}(111)$ and (c) Ni(111) with one substitution atom of four types (Fig. S1) are shown.

or stretched, which results in a change of the adsorption energy. It is named as the geometric effect. To take the geometric effect into account, the relationship between the change of the lattice constant of each metal and the adsorption energy of the adsorbate needs to be unravelled. To this end, the lattice constant of each metal was varied from $-1.5 \%$ to $1.5 \%$ based on the optimized unit cell and the adsorption energies of $O$ on the surfaces with the different lattice constants were calculated. It is found that the adsorption energies on all the metals are linearly correlated to the relative lattice constants (Fig. S2), which is consistent with the work in the literatures38, 39. We find that a descriptor to quantify the geometric effect can be obtained (see Eq. S3 in the SI). It is interesting to note that the geometric effect is significant when the noble metal solutes are added to the metal surface (the geometric effects of $\mathrm{Au}$ in Pt-base, Rh-base and Ni-base are $0.324 \mathrm{eV}, 0.567 \mathrm{eV}$ and $1.076 \mathrm{eV}$, respectively). While for Pt-base and Rh-base alloys, the geometric effect is relatively small, for Ni-base alloys, the geometric effect is crucial.

The solute atoms can also affect the electronic structure of the base metal, which is named as the electronic effect. The electronic effect can be quantitatively considered as follows: Following the procedure in Fig. S3, the bonding energy of a solute atom with a surface can be acquired by calculating the difference of the total energies of the surface before and after the removal of the single atom. The electronic effect can be measured by the difference between the bonding energies of the pure base metal and the solute metal (see Eq. S5 in the SI).

Having achieved a breakthrough of obtaining the structure-energy descriptor for many alloy catalysts to predict the chemisorption energies of $\mathrm{C}, \mathrm{O}$ and NO, we then used NO oxidation as an example to test a possible strategy for alloy catalyst design, which is illustrated as follows. Firstly, using microkinetic modelling we calculated the TOFs of NO oxidation as functions of chemisorption energies of $\mathrm{NO}$ and $\mathrm{O}$, respectively, utilising the BEP relations (Fig. $\mathrm{S7}$ ). A volcano surface of TOF was generated in the range of NO chemisorption energies from $-2.5 \mathrm{eV}$ to $0 \mathrm{eV}$ and $\mathrm{O}$ from $-2.0 \mathrm{eV}$ to $-0.5 \mathrm{eV}$, as 


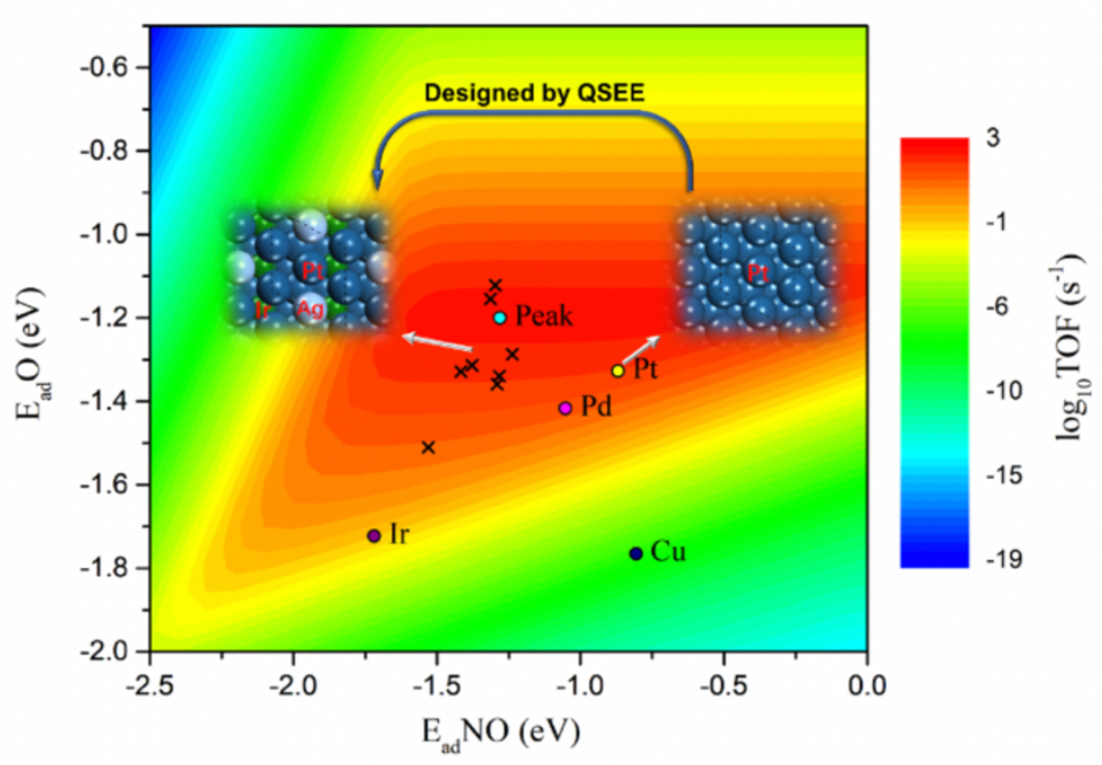

Fig. 3 Volcano surface of NO oxidation, which shows the logarithm of TOF as functions of the adsorption energies of $\mathrm{NO}$ and $\mathrm{O}$. The activities from pure Pt, $\mathrm{Pd}$ and peak point are indicated on the map. The chemisorption energies of designed alloys are marked by crosses. The structures of the high performance catalyst designed from pure $\mathrm{Pt}$ is shown.

shown in Fig. 3. The TOFs of $\mathrm{Pt}(111)$ and $\mathrm{Ni}(111)$ were obtained to be $4.93 \mathrm{~s}-1$ and $6.97 \times 10-7$ $\mathrm{s}-1$, respectively. From Fig. 3, the peak of the volcano surface is located at $(-1.28 \mathrm{eV}(\mathrm{X}),-1.20$ $\mathrm{eV}(\mathrm{Y}))$ with the TOF of $\sim 102 \mathrm{~s}-1$, which are the desirable chemisorption energies. Therefore, the most active alloy catalyst should have the adsorption energies of $-1.28 \mathrm{eV}$ for $\mathrm{NO}$ and $1.20 \mathrm{eV}$ for $\mathrm{O}$, respectively.

To design alloy catalysts for NO oxidation, up to three solute metals were added in the Pt and $\mathrm{Ni}$ systems to form Pt-based alloys and Ni-based alloys, because Pt has high activity for NO oxidation 31 and $\mathrm{Ni}$ is a cheap metal. For each base, it generates $96,768\left(123 \times \mathrm{C}_{-} 8^{\wedge} 3\right)$ different alloy combinations, which should be sufficient to locate the active alloy catalysts. In this work, only the adsorption energies around the peak point $(-1.28 \mathrm{eV},-1.20 \mathrm{eV})$ were considered. Then, based on the results of the QSEE six most active catalysts from Pt-based alloys were selected, while two catalysts from Ni-based alloys were chosen as the examples. The chemisorption energies of $\mathrm{NO}$ and $\mathrm{O}$ on these designed catalysts were also carried out using DFT, the results of which are illustrated in Fig. 3 by crosses, illustrating that they are very close to the peak of the volcano surface.

To obtain more accurate results, the reactions on these eight designed catalysts were further calculated rigorously (partial structures are shown in Fig. 4 and S6). The transition states of $\mathrm{O} 2$ dissociation and NO oxidation were computed by DFT (the structures are illustrated in Fig. S5) and the TOF of each catalyst was obtained using microkinetic modelling. The reaction barriers and TOFs of six most active Pt-based alloys and two Ni-based alloys were listed in Table S2.

It is clear from Table S2 that the TOFs of these six Pt-based alloys are clearly much higher than that of the pure Pt metal (4.93 s-1), and two of the highest TOFs in these catalysts (900s-1 and $205 \mathrm{~s}-1)$ reach the theoretical maximum value ( 102 s-1) on the volcano surface. To further understand this result, the energy profiles of $\mathrm{Pt}(111)$ and the designed alloy with the highest TOF are compared (Fig. 4). The $\mathrm{O} 2$ dissociation barrier on this alloy is $0.3 \mathrm{eV}$ lower 
than that of $\mathrm{Pt}(111)$, leading to the reaction rate of the alloy to be faster. The adsorption energy of $\mathrm{NO}$ is also stronger on the alloy, avoiding the catalyst-poison by oxygen due to more NO molecules adsorbed on the surface. Moreover, for Ni-based alloys, the TOFs of these two samples (1.307 s-1 and $0.049 \mathrm{~s}-1$ ) were more than five orders of magnitude higher than that of the pure Ni metal $(6.97 \times 10-7 \mathrm{~s}-1)$, which is a significant improvement.

It is worth mentioning that all the alloys with the excellent catalytic performances discovered in this work, as listed in Table S2, were unknown structures before our design process; they were created during the design procedure, illustrating that the strategy in our work possesses a strong design nature. As shown in the inserts of Fig. 4 and S6, some of designed catalysts are not trivial structures, exhibiting the effectiveness of the approach.

In summary, a catalyst structure-energy descriptor (i.e. QSEE) was derived and was tested for many alloys including $3 \mathrm{~d}, 4 \mathrm{~d}$ and $5 \mathrm{~d}$ transition metals with 12 solute metals. Good correlations between the predicted chemisorption energies from the QSEE and those from DFT calculations for the adsorbates tested were found. Then the structure-energy descriptor was used to design

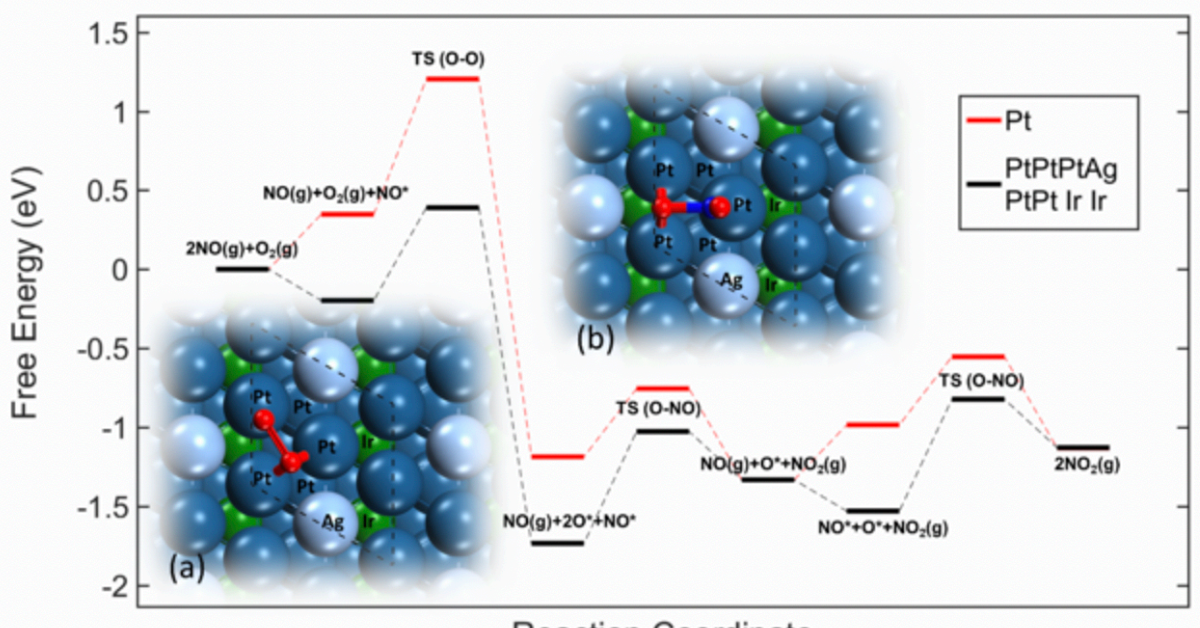

Reaction Coordinate

Fig. 4 Energy profiles of NO oxidation on Pt(111) (red line) and the designed alloy (first layer: PtPtPtAg//second layer: PtPtIrIr) (black line). In the transition state structures of (a) $\mathrm{O}_{2}$ dissociation and (b) $\mathrm{NO}$ oxidation on the alloy, the $\mathrm{O}$ and $\mathrm{N}$ are in the red and blue, respectively, while the metals are marked inside.

alloy catalysts for NO oxidation as an example. Full DFT calculations with microkinetic simulations show that the activities of all the designed alloys are much higher than pure metal counterparts. The TOFs of the designed two Ni-based alloys are five orders of magnitude higher than the pure Ni catalyst.

As metal alloy catalysts are arguably the most common catalysts in heterogeneous catalysis, a breakthrough on alloy catalysts should have high impacts in the field. This work demonstrates a possibility for the true rational design of catalysts.

The authors gratefully acknowledge the UK's national high performance computing services ARCHER (EP/P022561/1), Thomas (EP/P020194/1) and QUB high performance computing centre for computing resources.

\section{Conflicts of interest}

There are no conflicts to declare. 


\section{Notes and references}

1 A. Michaelides, Z. P. Liu, C. J. Zhang, A. Alavi, D. A. King and P. Hu, J. Am. Chem. Soc., 2003, 125, 3704.

2 R. A. van Santen, M. Neurock and S. G. Shetty, Chem. Rev., 2010, 110, 2005.

3 V. Pallassana and M. Neurock, J. Catal., 2000, 191, 301.

4 Z.-P. Liu and P. Hu, J. Chem. Phys., 2001, 114, 8244.

5 A. Logadottir, T. H. Rod, J. K. Nørskov, B. Hammer, S. Dahl and C. J. H. Jacobsen, J. Catal., 2001, 197, 229.

6 F. Abild-Pedersen, J. Greeley, F. Studt, J. Rossmeisl, T. R. Munter, P. G. Moses, E. Skulason, T. Bligaard and J. K. Norskov, Phys. Rev. Lett., 2007, 99, 016105.

7 F. Calle-Vallejo, D. Loffreda, M. T. Koper and P. Sautet, Nature Chem., 2015, 7, 403.

8 M. M. Montemore and J. W. Medlin, Catal. Sci. Technol., 2014, 4, 3748.

9 J. Cheng, P. Hu, P. Ellis, S. French, G. Kelly and C. M. Lok, J. Phys. Chem. C, 2008, 112, 1308.

10 T. Bligaard, J. K. Nørskov, S. Dahl, J. Matthiesen, C. H. Christensen and J. Sehested, J. Catal., 2004, 224, 206.

11 J. S. Hummelshoj, F. Abild-Pedersen, F. Studt, T. Bligaard and J. K. Norskov, Angew. Chem. Int. Ed., 2012, 51, 272.

12 J. K. Norskov, T. Bligaard, J. Rossmeisl and C. H. Christensen, Nature Chem., 2009, 1, 37.

13 B. Yang, R. Burch, C. Hardacre, G. Headdock and P. Hu, ACS Catal., 2014, 4, 182.

14 Y. Hou, D. Wang, X. H. Yang, W. Q. Fang, B. Zhang, H. F. Wang, G. Z. Lu, P. Hu, H. J. Zhao and H. G. Yang, Nat. Commun., 2013, 4, 1583.

15 K. Tran and Z. W. Ulissi, Nature Catal., 2018, 1, 696.

16 T. A. A. Batchelor, J. K. Pedersen, S. H. Winther, I. E. Castelli, K. W. Jacobsen and J. Rossmeisl, Joule, 2019, 3, 834.

17 Z. Li, S. Wang, W. S. Chin, L. E. Achenie and H. Xin, J. Mater. Chem. A, 2017, 5, 24131.

18 H. Xin, A. Holewinski and S. Linic, ACS Cataly., 2011, 2, 12.

19 T. S. Choksi, L. T. Roling, V. Streibel and F. Abild-Pedersen, J. Phys. Chem. Lett., 2019, 10, 1852.

20 M. Andersen, S. V. Levchenko, M. Scheffler and K. Reuter, ACS Catal., 2019, 9, 2752.

21 B. Hammer and J. K. Norskov, Adv. Catal., 2000, 45, 71.

22 J. K. Norskov, F. Abild-Pedersen, F. Studt and T. Bligaard, Proceedings of the National Academy of Sciences of the United States of America, 2011, 108, 937.

23 F. Calle-Vallejo, J. I. Martinez, J. M. Garcia-Lastra, P. Sautet and D. Loffreda, Angew. Chem. Int. Ed., 2014, 53, 8316.

24 F. Calle-Vallejo, J. Tymoczko, V. Colic, Q. H. Vu, M. D. Pohl, K. Morgenstern, D. Loffreda, P. Sautet, W. Schuhmann and A. S. Bandarenka, Science, 2015, 350, 185.

25 Z. Wang and P. Hu, Phys. Chem. Chem. Phys., 2017, 19, 5063.

26 J. H. Pazmiño, J. T. Miller, S. S. Mulla, W. Nicholas Delgass and F. H. Ribeiro, J. Catal., 2011, 282, 13.

27 P. S. Metkar, V. Balakotaiah and M. P. Harold, Catal. Today, 2012, 184, 115.

28 Z. Hong, Z. Wang and X. Li, Catal. Sci. Technol., 2017, 7, 3440.

29 S. Roy and A. Baiker, Chem. Rev., 2009, 109, 4054.

30 G. Liu and P.-X. Gao, Catal. Sci. Technol., 2011, 1, 552.

31 H. Wang, Y. Guo, G. Lu and P. Hu, J. Chem. Phys., 2009, 130, 224701.

32 N. D. Wasalathanthri, T. M. SantaMaria, D. A. Kriz, S. L. Dissanayake, C.-H. Kuo, S. Biswas and S. L. Suib, Appl. Catal. B., 2017, 201, 543.

33 J. E, L. Xie, Q. Zuo and G. Zhang, Atmos. Pollut. Res., 2016, 7, 9.

34 C. Liu, J.-W. Shi, C. Gao and C. Niu, Appl. Catal. A., 2016, 522, 54.

35 J. P. S. Sousa, M. F. R. Pereira and J. L. Figueiredo, Catal. Today, 2011, 176, 383.

36 L. Li, Q. Shen, J. Cheng and Z. Hao, Appl. Catal. B., 2010, 93, 259.

37 P. Forzatti, L. Castoldi, I. Nova, L. Lietti and E. Tronconi, Catal. Today, 2006, 117, 316.

38 M. Mavrikakis, B. Hammer and J. K. Nørskov, Phys. Rev. Lett., 1998, 81, 2819.

39 M. J. D. Rushton, A. Chroneos, S. J. Skinner, J. A. Kilner and R. W. Grimes, Solid State Ion., 2013, 230, 37. 


\section{Supporting Information}

\section{Achieving Rational Design of Alloy Catalysts Using a Descriptor Based on the Quantitative Structure-energy Equation}

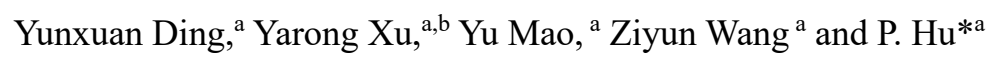

a. School of Chemistry and Chemical Engineering, The Queen's University of Belfast, Belfast, BT9 $5 A G, U K$.

b. Research Institute of Urumqi Petrochina Chemical Company, China

Email:p.hu@qub.ac.uk 


\section{S1. Computational Methods}

All the DFT calculations in the work were carried out with a periodic slab model using the Vienna ab initio simulation program (VASP) ${ }^{1,2}$. The projector-augmented wave (PAW) method $^{2,3}$ was utilized to describe the electron-ion interactions, and the cut-off energy of plane-wave basis expansion was set to be $450 \mathrm{eV}$. For the exchange and correlation functional, the generalized gradient approximation (GGA) was used with Perdew-BurkeErnzerhof $(\mathrm{PBE})^{4}$. The surfaces were modeled by using a periodic slab consisting of 4-layers of metal atoms with the 2 lower layers fixed and the 2 upper layers relaxed. A $p(2 \times 2)$ supercell was chosen with $4 \times 4 \times 1$ Monkhorst-Pack $k$-point mesh sampling for Brillouinzone integration. $A \sim 12 \AA$ vacuum layer was placed on all the surfaces. In the spin-polarized calculations, the free molecules of $\mathrm{O}_{2}$ and $\mathrm{NO}$ were placed in a $(10 \times 10 \times 10) \AA^{3}$ cubic box to minimize the interaction of neighboring molecules. The optimized structures were reached when the force on the relaxed atoms became less than $0.05 \mathrm{eV} / \AA$. HSE06 was also used to calculate the reaction barrier of NO oxidation on $\mathrm{Pt}(111)$ as a comparison (see S4).

In this work, the relative adsorption energies of an adsorbate $\left(\Delta E_{a d}\right)$ are calculated with respect to the adsorption energy of this adsorbate on the pure metal close-packed surface $\left(E_{a d-b a s e}\right)$, as follows:

$$
\Delta E_{a d}=E_{\text {adsorbate+surface }}-E_{\text {adsorbate }}-E_{\text {surface }}-E_{\text {ad-base }}
$$

The transition states (TSs) were located with a constrained minimization technique ${ }^{5-7}$. In order to calculate the free energies of the surface species, zero-point-energy (ZPE), thermal energy and entropy derived from partition function were introduced to obtain the corrections ${ }^{8}$, 9 . As for gaseous species, the thermodynamic corrections were calculated using the Gaussian 03 software package with the ideal gas approximation. Taking the $\mathrm{NO}$ oxidation as an example, the temperature of NO oxidation was set to be $600 \mathrm{~K} ; 0.10 \mathrm{bar}, 3 \times 10^{-4}$ bar and $1.7 \times 10^{-4}$ bar were used for the partial pressures of $\mathrm{O}_{2}, \mathrm{NO}$ and $\mathrm{NO}_{2}$, respectively ${ }^{10}$. The high temperature resulted in a low coverage on the surface; thus, the influence of the coverage can be neglected. To simplify the procedure, the coverage effect was ignored. In the microkinetic modeling, three elementary steps (NO adsorption, $\mathrm{O}_{2}$ dissociation and $\mathrm{NO}$ oxidation) were considered:

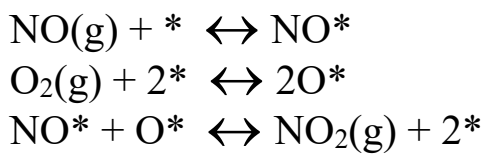

All the thermodynamic corrections were taken into account and full micro-kinetic modeling ${ }^{11}$, ${ }^{12}$ was carried out to calculate the turn-over frequency (TOF) and generate the volcano curve surface. The micro-kinetics modeling was performed using the code developed by our group $^{13}$.

\section{S2. Derivation for the Quantitative Structure-Energy Equation}

\section{The Bonding Contribution Equation}

On the purpose of easier comparison, the bonding contribution equation is illustrated below with the same symbol definitions in this work: 


$$
\Delta E_{a d}=\sum_{i=1}^{n} g \times a_{i} \times \Delta E_{M}
$$

where $g$ is the generalized parameter, $a_{i}$ is the bond-counting contribution factor of different substitution type $i$ and $\Delta E_{M}$ is the difference between the adsorption energy of the pure metal $\mathrm{M}$ and the adsorption energy of the pure base metal ${ }^{14}$.

\section{Geometric Effect}

After systematically study the adsorbate on the alloy surface, there are four possible substitution types (Fig. S1). To quantify the geometric effect of the base metal replaced by one solute atom, we take the lattice constant for the original bulk to be a variable with the surface structure relaxed to be optimized. Using the calculated lattice constants $\left(\mathrm{d}_{\mathrm{eq}}\right)$ for bulk $\mathrm{Pt}(111), \mathrm{Rh}(111)$ and $\mathrm{Ni}(111)$ as the equilibrium lattice constants, which are $2.805 \AA, 2.704$ $\AA$ and $2.487 \AA$, respectively, the bond distance (d) between the base atom and solute atom can be compared with $\mathrm{d}_{\mathrm{eq}}$ as shown in Table $\mathrm{S} 1$ : The maximum value of the relative lattice constant $\left(\left(\mathrm{d}-\mathrm{d}_{\mathrm{eq}}\right) / \mathrm{d}_{\mathrm{eq}}\right)$ is around $1.5 \%$, except $\mathrm{Ni}-\mathrm{Ag}$ alloy, which is nearly $3 \%$. However, the calculated surface segregation energy for Ag atom at the close-packed Ni(111) surface was $0.80 \mathrm{eV} /$ atom, which displayed a very strong segregation, indicating that the prediction for $\mathrm{Ni}-\mathrm{Ag}$ alloy components was completely invalidated ${ }^{15}$. Thus, type I for Ag solute is removed from Ni-base alloy. All the lattice constants vary from $-1.5 \%$ to $1.5 \%$ in this work. As can be seen from Table S1, most of the transition metal solutes substituted in the pure bases only have a small effect on the lattice constants. However, when noble metals (Ag and $\mathrm{Au}$ ) are added into the system, this geometric effect is significant.

To quantitatively determine the influence of the lattice constants on the adsorption energies, the relative lattice constants of the pure metal bulks are changed from $-1.5 \%$ to $1.5 \%$, and the chemisorption energies were calculated as a function of the relative lattice constants. As shown in Fig. S2, the adsorption energy of each transition metal as a function of the relative lattice constant has its own slope. The adsorption energies become weak when the lattice constants are compressed; while the lattice constants are stretched, the interaction between adsorbate and surface is stronger, leading to the negative slopes. 


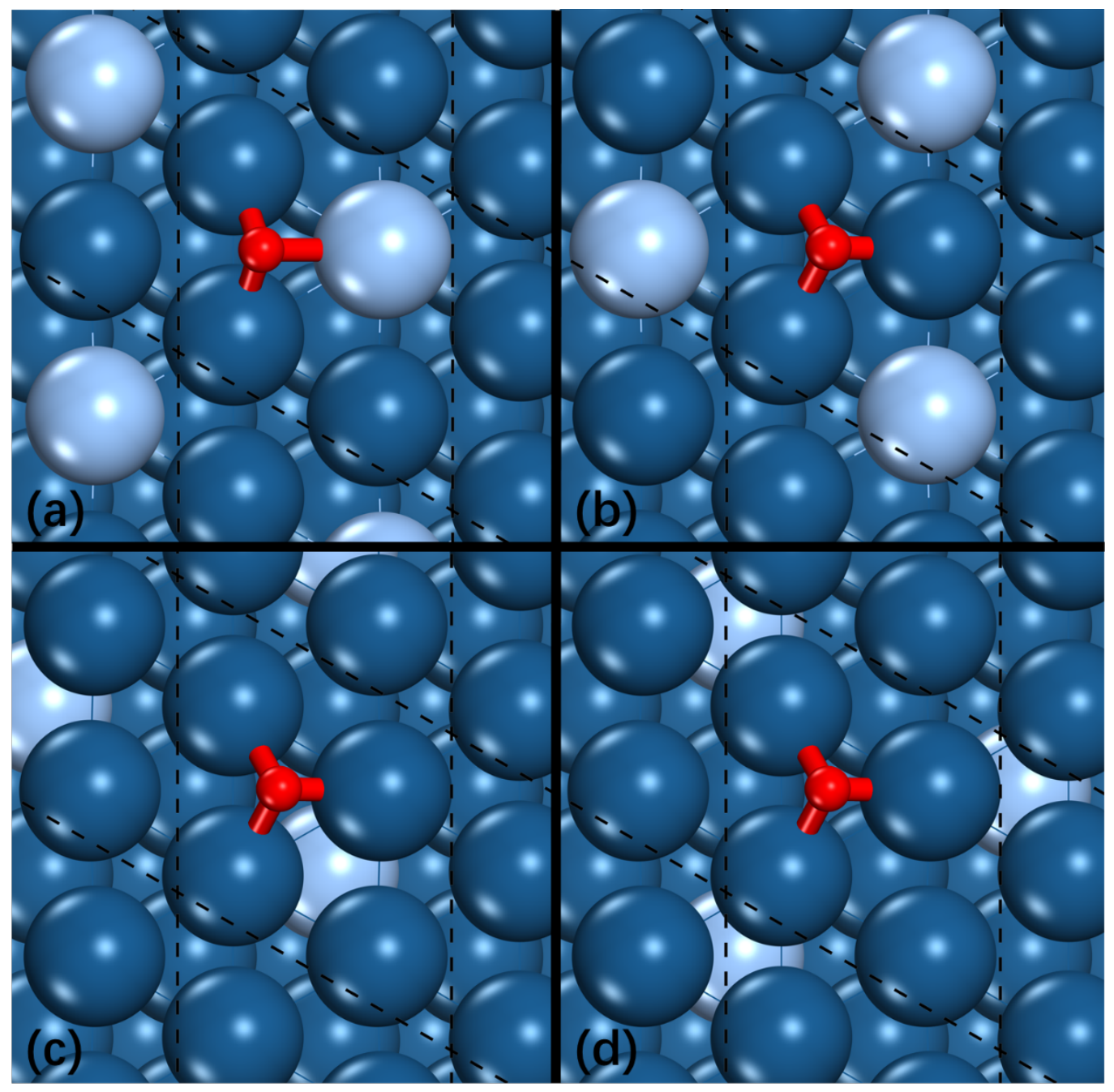

Fig. S1 Four possible substitution types of the one solute Pt-based alloys. In the alloy structures of (a) type I, (b) type II, (c) type III, and (d) type IV, the O, Pt and Ag are in red, dark blue and silver, respectively.

Table S1 The lattice constants for different alloy surfaces ( $\mathrm{Pt}, \mathrm{Rh}$ and $\mathrm{Ni}$ ) substituted with one solute metal (Co, $\mathrm{Ni}, \mathrm{Cu}, \mathrm{Ru}, \mathrm{Rh}, \mathrm{Pd}, \mathrm{Ag}, \mathrm{Re}, \mathrm{Os}, \mathrm{Ir}, \mathrm{Pt}$ and $\mathrm{Au}$ ) are described by the bond distance between the base metal atom and solute atom $\left(\mathrm{d}_{\text {Base- } \mathrm{M}}\right)$. The relative lattice constants are defined as the percentage of the difference between the alloy bond distance and the pure base bond distance.

\begin{tabular}{|c|c|c|c|c|c|c|}
\hline Solute & dPt-M & $\left(d-d_{e q}\right) / d_{e q} \%$ & $\mathbf{d}_{\mathrm{Rh}-\mathrm{M}}$ & $\left(d-d_{\text {eq }}\right) / d_{\text {eq }} \%$ & $\mathbf{d}_{\mathrm{N} \mathrm{i}-\mathrm{M}}$ & $\left(\mathbf{d}-\mathbf{d}_{\mathrm{eq}}\right) / \mathbf{d}_{\mathrm{eq}} \%$ \\
\hline Co & 2.809 & 0.14 & 2.705 & 0.04 & 2.487 & 0.00 \\
\hline
\end{tabular}




\begin{tabular}{lllllll}
\hline $\mathbf{N i}$ & 2.808 & 0.11 & 2.705 & 0.04 & $\mathbf{2 . 4 8 7}$ & $\mathbf{0 . 0 0}$ \\
$\mathbf{C u}$ & 2.805 & 0.00 & 2.705 & 0.04 & 2.490 & 0.12 \\
$\mathbf{R u}$ & 2.809 & 0.14 & 2.705 & 0.04 & 2.488 & 0.04 \\
$\mathbf{R h}$ & 2.807 & 0.07 & $\mathbf{2 . 7 0 4}$ & $\mathbf{0 . 0 0}$ & 2.488 & 0.04 \\
$\mathbf{P d}$ & 2.807 & 0.07 & 2.707 & 0.11 & 2.496 & 0.36 \\
$\mathbf{A g}$ & 2.830 & 0.89 & 2.745 & 1.52 & 2.563 & 3.06 \\
$\mathbf{R e}$ & 2.814 & 0.32 & 2.706 & 0.07 & 2.490 & 0.12 \\
$\mathbf{O s}$ & 2.813 & 0.29 & 2.706 & 0.07 & 2.488 & 0.04 \\
$\mathbf{I r}$ & 2.810 & 0.18 & 2.705 & 0.04 & 2.487 & 0.00 \\
$\mathbf{P t}$ & $\mathbf{2 . 8 0 5}$ & $\mathbf{0 . 0 0}$ & 2.705 & 0.04 & 2.488 & 0.04 \\
$\mathbf{A u}$ & 2.817 & 0.43 & 2.720 & 0.59 & 2.522 & 1.41 \\
\hline
\end{tabular}
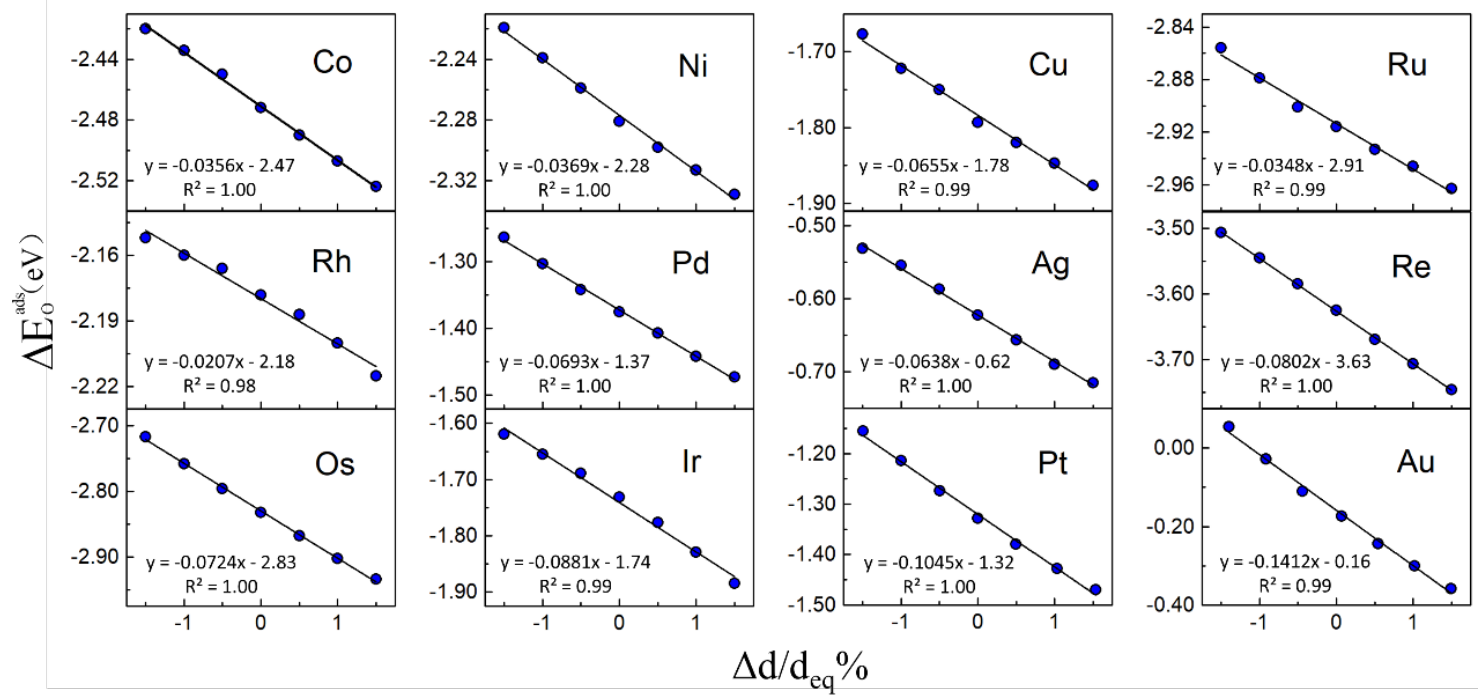

Fig. S2 Graphs to show how the relative lattice constants affect the adsorption energies of an oxygen atom adsorbed on $\mathrm{Co}(0001), \mathrm{Ni}(111), \mathrm{Cu}(111), \mathrm{Ru}(0001), \mathrm{Rh}(111), \operatorname{Pd}(111), \operatorname{Ag}(111), \operatorname{Re}(0001), \operatorname{Os}(0001), \operatorname{Ir}(111)$, $\mathrm{Pt}(111)$ and $\mathrm{Au}(111)$.

The geometric effect should be affected by the base metal and the solute metal, which indicates that the lattice constant of the base and solute metals should both involve in the equation. To quantify the geometric effect, the averaged bond distance of the pure solute and base metals is used. By comparing the averaged bond distance and the bond distance of the pure solute metal, we can easily obtain the difference between the adsorption energy of the alloy and the pure metal from Fig. S2, which can be calculated by the equation below.

$$
E_{\text {Base-M }}^{\text {geo }}=\lambda_{M} \times\left[\left(d_{M}+d_{\text {Base }}\right) / 2-d_{M}\right] / d_{M}
$$

where $\lambda_{M}$ is the gradient of the relative lattice constant affecting the adsorption energy, while $d_{M}$ and $d_{\text {Base }}$ are the bond distances of the solute metal and the base metal, respectively.

\section{Electronic Effect}

Not only has the geometry of the surface changed, but also the electronic environment of the slab has changed by other metals introduced. Thomson and co-workers ${ }^{16}$ found that the binding ability between the adsorbate and the alloy will increased, when the proportion of $\mathrm{Pt}$ 
alloys contained more $\mathrm{Au}\left(\mathrm{PtAu}_{2}>\mathrm{Pt}_{2} \mathrm{Au}>\mathrm{Pt}_{3}>\mathrm{Au}_{3}\right)$. $\mathrm{Au}$ is inert for adsorbates comparing with Pt, and thus the binding affinity of Pt alloy can be intrinsically affected by the Au solute. This indicates that the solute metal can influence the intrinsic bonding energy of the base metal. The difference between the bonding energy before and after adding the solute metal should not be ignored. The bonding energy is obtained from Eq. S4:

$$
E_{\text {bond }}=E_{M}-E_{M \text {-vacancy }}-E_{M \text {-atom }}
$$

where $\mathrm{E}_{\mathrm{M}}, \mathrm{E}_{\mathrm{M} \text {-vacancy }}$ and $\mathrm{E}_{\mathrm{M} \text {-atom }}$ are the optimization energies of the system, the system with an atom removed and the atom, respectively. The system with an atom removed is illustrated in Fig. S3.

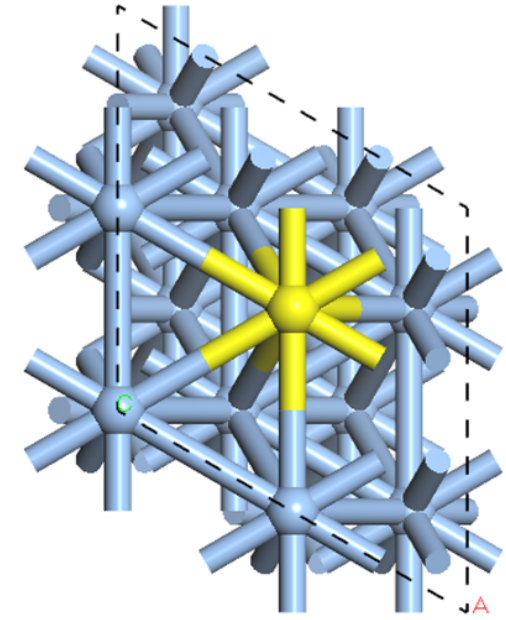

(a)

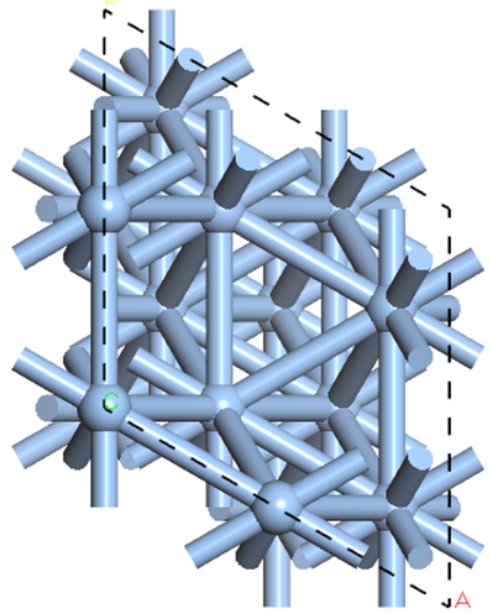

(b)

Fig. S3 Taking Ag as an example, the total energy is from (a) $\operatorname{Ag}(111) p(2 \times 2)$ surface, while the vacancy energy is from (b) the surface with one Ag atom removed. Silver and yellow atoms refer to Ag and the removed atom, respectively.

The difference of the bonding energy between the base metal and the solute metal can be calculated by Eq. S5, which is named as the electronic effect.

$$
\Delta E_{\text {Base-M }}^{\text {ele }}=\left(E_{\text {Base }}-E_{\text {Base-vacancy }}-\frac{E_{\text {Base-bulk }}}{n}\right)-\left(E_{M}-E_{M \text {-vacancy }}-\frac{E_{M-b u l k}}{n}\right)
$$

where $E_{\text {Base }}$ is the total energy for the base metal surface, $E_{\text {Base-vacancy }}$ and $E_{M \text {-vacancy }}$ are the total energies with one atom removed from the pure base metal and pure solute metal, respectively. $\frac{E_{\text {Base-bulk }}}{n}$ and $\frac{E_{M-b u l k}}{n}$ stand for the energies of the base metal and the solute metal per atom, respectively ${ }^{17}$. $E_{b u l k}$ is the energy of each unit-cell.

\section{Quantitative Structure-Energy Equation}

Combining the bonding, geometric and electronic effects, we can finally obtain the quantitative structure-energy equation (Eq. 1 in the main text). $a_{i}$ is the coefficient of the bonding effect of type $i$, which are $7 / 27,-6 / 27,-2 / 27$ and $-3 / 27$ for type I, II, III and IV, respectively ${ }^{14} . \Delta E_{M}, \Delta E_{\text {Base-M }}^{\text {ele }}$ and $E_{\text {Base-M }}^{\text {geo }}$ are the intrinsic activity of the pure solute metal, the difference of the bonding energy between the pure base metal and the solute metal, and 
the geometric effect caused by introducing the solute metals. The value of $\boldsymbol{b}$ is fitted to be 1.3 for the three base metals. The adsorption energies of all one atom substitution alloys are used to fit $c_{i}$ coefficients, which are $0,-4.5,1$ and 0 for type I, II, III and IV, respectively. The bonding effect for type I can be substantial for the adsorbate directly binding with the solute metal; while for type III and type IV, the contributions of the geometric effect are small for the solute metal in the subsurface. This is due to the neighboring base metal atoms forming a highly stable shell-like structure around the solute atom. For NO molecule, the experimental work ${ }^{18}$ showed that NO adsorbed on Pt and Rh metals at the top site. Therefore, we placed

NO at the top site ${ }^{19}$. Thus, $a_{i}$ for all types I, II, III and IV are $1,-2 / 9,-1 / 9,1 / 10$,

respectively ${ }^{4}$. The carbon atom adsorbing at the hcp site ${ }^{20,21}$ has the same $a_{i}$ as the oxygen. The electronic effect is mainly an intrinsic property of the alloys; therefore, the values of the electronic effect are kept constant for different adsorbates for simplicity. The relative adsorption energies of $\mathrm{C}$ adsorbed on Pt-based alloys with one solute metal $(\mathrm{Ni}, \mathrm{Cu}, \mathrm{Ru}, \mathrm{Rh}$, $\mathrm{Pd}, \mathrm{Ag}$, Os, $\mathrm{Ir}, \mathrm{Pt}$ and $\mathrm{Au}$ ) have a good correlation to the DFT calculated results with $\mathrm{R}^{2}$ of 0.82 (Fig. S4).

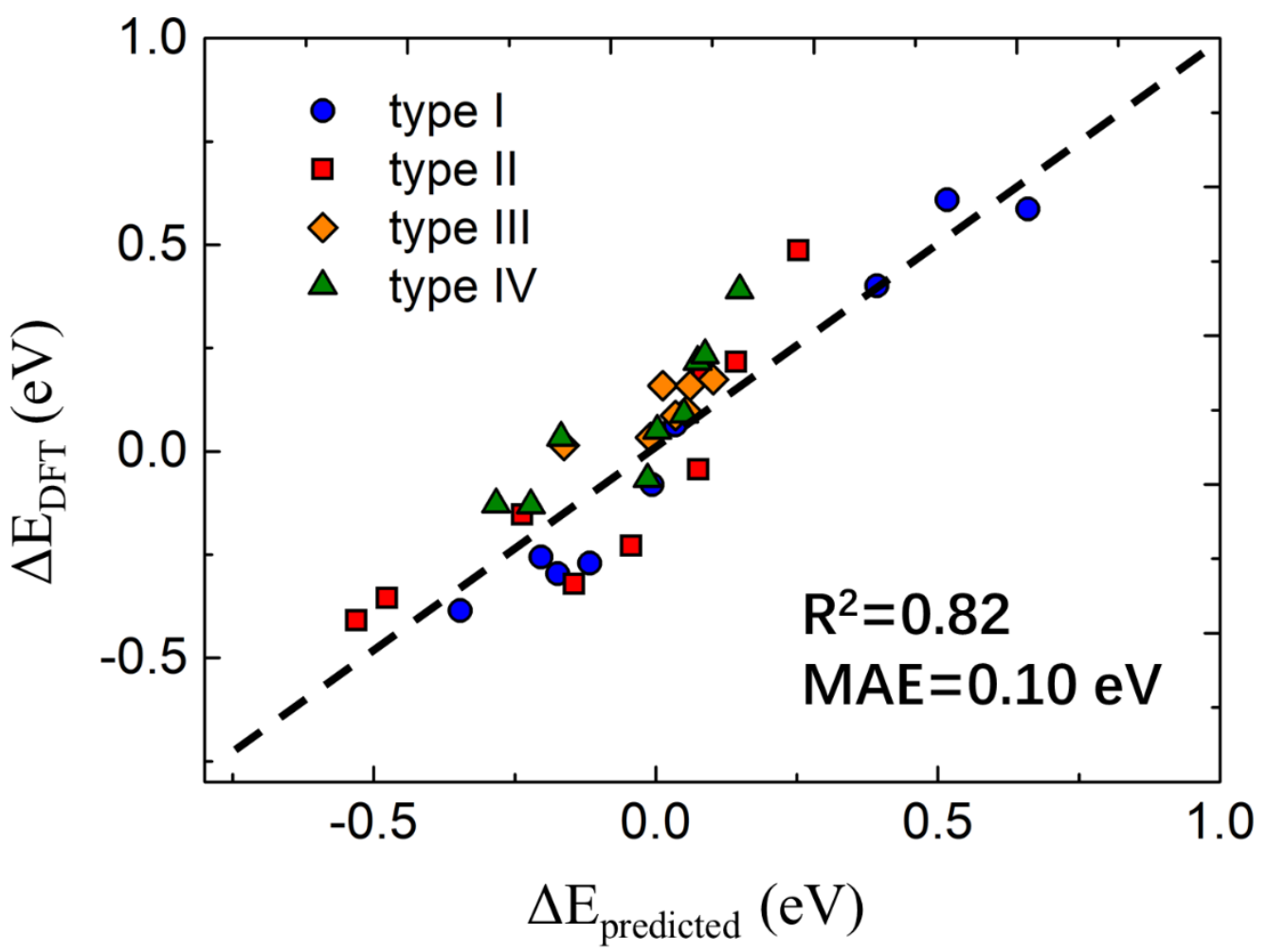

Fig. S4 Comparisons between the predicted relative adsorption energies of $\mathrm{C}$ on the Pt-based alloys from the quantitative structure-energy equation and those from DFT calculations. 


\section{S2. Structures and Data for the Designed Alloys}
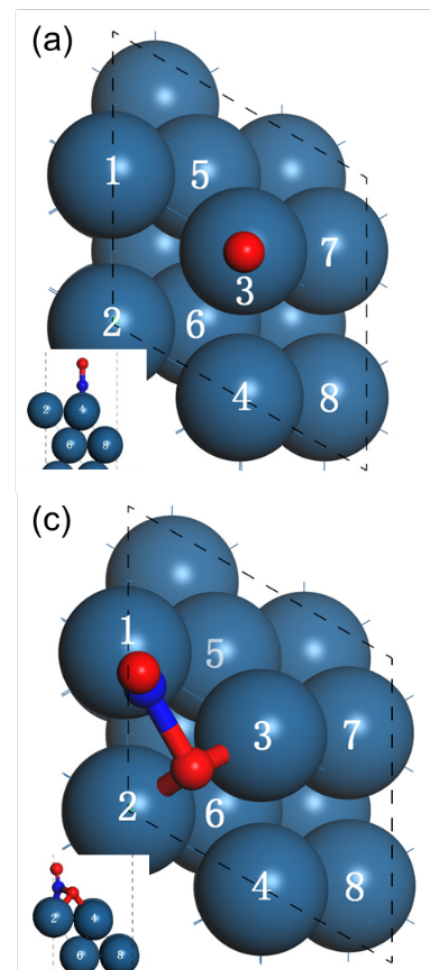
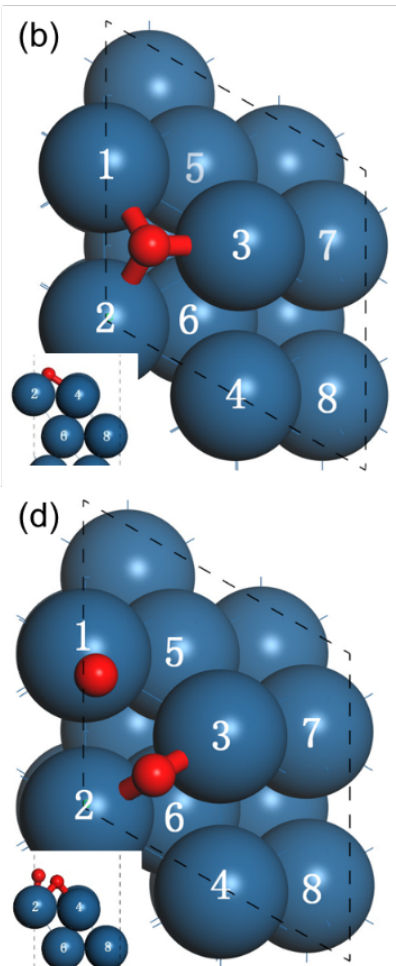

Fig. S5 Top and side (insert) views of (a) NO and (b) $\mathrm{O}$ adsorbed on the $p(2 \times 2) \mathrm{Pt}(111)$ surface. Top and side (insert) views of the transition states of (c) $\mathrm{NO}$ oxidation and (d) $\mathrm{O}_{2}$ dissociation. Pt atom, oxygen atom and nitrogen atom are in dark blue, red and blue, respectively. First and second layer of $\mathrm{Pt}$ atoms are numbered from 1 to 4 and 5 to 8 .

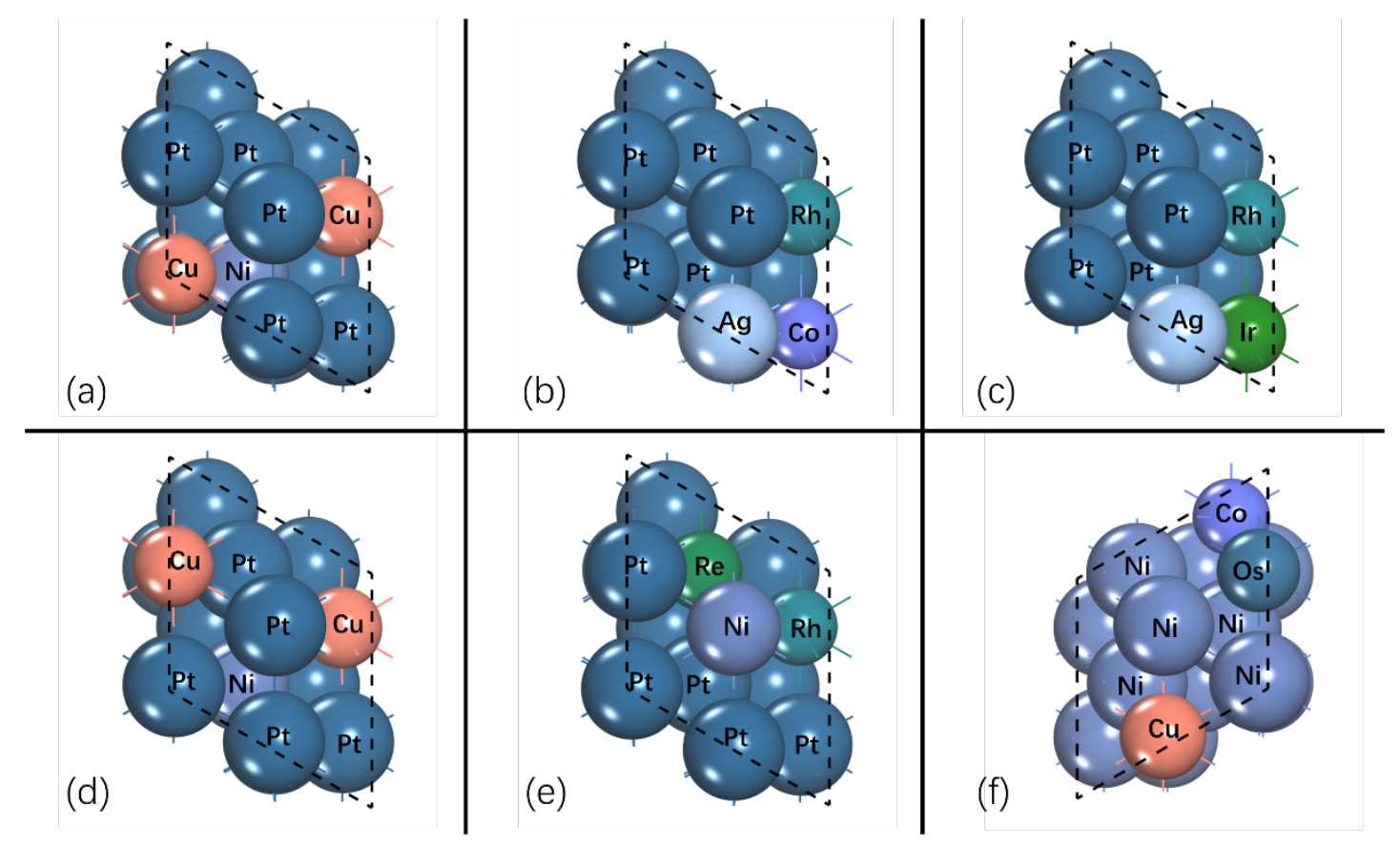

Fig. S6 Partial structures of the alloys in Table S2. The metals are marked inside.

Table S2 The adsorption energies of $\mathrm{O}\left(\mathrm{E}_{\mathrm{ad}}(\mathrm{O})\right)$ and $\mathrm{NO}\left(\mathrm{E}_{\mathrm{ad}}(\mathrm{NO})\right)$, the reaction barriers of $\mathrm{O}_{2}$ dissociation $\left(\mathrm{E}_{\mathrm{a}}(\mathrm{O}-\mathrm{O})\right)$ and $\mathrm{NO}\left(\mathrm{E}_{\mathrm{a}}(\mathrm{O}-\mathrm{NO})\right)$ oxidation, and TOF from each alloy. The atoms on the first and second layers are listed, and structures are shown in Fig. S5. The units of energies and TOF are $\mathrm{eV}$ and s${ }^{-1}$, respectively. The 
activities are calculated under typical experimental conditions $\left(\mathrm{T}=600 \mathrm{~K}, \mathrm{P}_{\mathrm{O} 2}=0.10\right.$ bar, $\mathrm{P}_{\mathrm{NO}}=3 \times 10^{-4}$ bar and $\mathrm{P}_{\mathrm{NO} 2}=1.7 \times 10^{-4}$ bar).

\begin{tabular}{|c|c|c|c|c|c|c|}
\hline \multicolumn{2}{|c|}{ Structure } & \multirow{2}{*}{$\mathbf{E}_{\mathbf{a d}}(\mathbf{O})$} & \multirow{2}{*}{$\mathbf{E}_{\text {ad }}$ (NO) } & \multirow{2}{*}{$\mathrm{E}_{\mathrm{a}}(\mathrm{O}-\mathrm{O})$} & \multirow{2}{*}{$\mathbf{E}_{\mathrm{a}}(\mathrm{O}-\mathrm{NO})$} & \multirow{2}{*}{ TOF } \\
\hline First layer & Second layer & & & & & \\
\hline PtPtPtAg & PtPtIrIr & -1.33 & -1.42 & 0.59 & 0.71 & $9.00 \times 10^{2}$ \\
\hline PtCuPtPt & PtNiCuPt & -1.12 & -1.30 & 1.15 & 0.69 & $2.05 \times 10^{2}$ \\
\hline PtPtPtAg & PtPtRhCo & -1.29 & -1.24 & 0.60 & 0.63 & $3.14 \times 10$ \\
\hline PtPtPtAg & PtPtRhIr & -1.31 & -1.38 & 0.57 & 0.77 & $1.57 \times 10$ \\
\hline CuPtPtPt & PtNiCuPt & -1.15 & -1.31 & 1.21 & 0.99 & $1.32 \times 10$ \\
\hline PtPtNiPt & RePtRhPt & -1.51 & -1.53 & 0.53 & 0.91 & 6.92 \\
\hline CuNiNiOs & NiNiNiCo & -1.34 & -1.28 & 1.09 & 0.79 & 1.31 \\
\hline CuNiNiOs & NiNiNiRu & -1.36 & -1.29 & 0.62 & 0.86 & $4.86 \times 10^{-2}$ \\
\hline
\end{tabular}

\section{S3. Rationale of the Volcano Surface}

In this work, $\mathrm{O}_{2}$ adsorption and $\mathrm{O}_{2}$ dissociation were combined, as well as $\mathrm{NO}$ oxidation and $\mathrm{NO}_{2}$ desorption. Thus, the rate equations for each elementary step were illustrated below:

$$
\begin{aligned}
& r_{1}=k_{1} P_{N O} \theta_{*}-k_{-1} \theta_{N O} \\
& r_{2}=k_{2} P_{O_{2}} \theta_{*}{ }^{2}-k_{-2} \theta_{O}{ }^{2} \\
& r_{3}=k_{3} \theta_{N O} \theta_{O}-k_{-3} P_{N O_{2}} \theta_{*}{ }^{2}
\end{aligned}
$$


where $k$ is the rate constant, $P$ is the partial pressure and $\theta$ is the coverage.
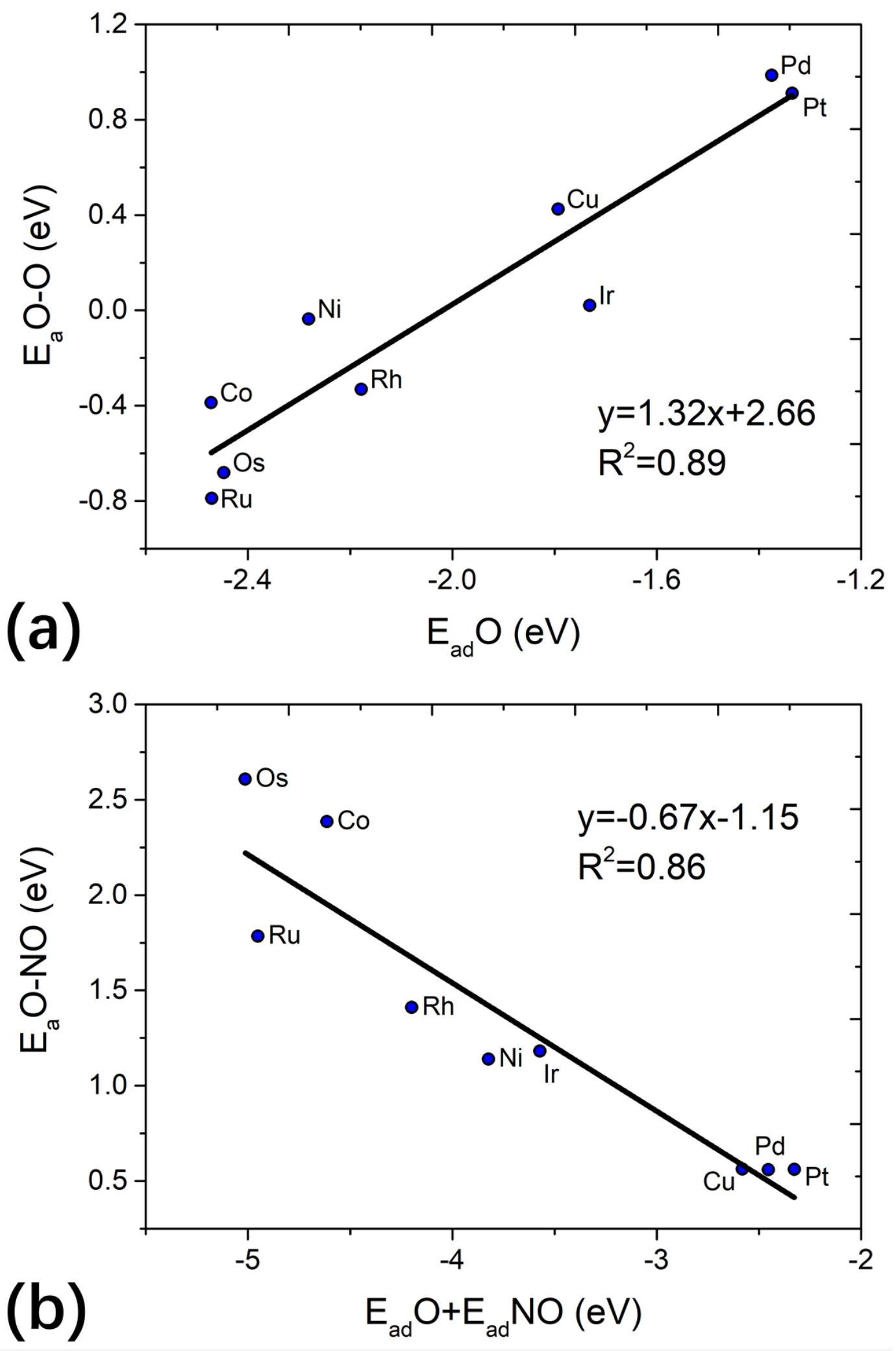

Fig. $\mathbf{S} 7 \mathrm{BEP}$ relations (a) between the adsorption energies of $\mathrm{O}$ and the reaction barriers of $\mathrm{O}_{2}$ dissociation, and (b) between the sum of adsorption energies of $\mathrm{NO}$ and $\mathrm{O}$ and the reaction barriers of $\mathrm{NO}$ oxidation. 


\section{S4. Comparison between PBE and HSE06 for NO Oxidation}

Table S3 Comparison of the NO oxidation barrier on Pt(111) between PBE and HSE functionals.

\begin{tabular}{cc}
\hline Functional & $\mathrm{E}_{\mathrm{a}}(\mathrm{O}-\mathrm{NO}) / \mathrm{eV}$ \\
\hline PBE & 0.55 \\
HSE06 & 0.51 \\
\hline
\end{tabular}

\section{Reference}

1. G. Kresse and J. Furthmüller, Phys. Rev. B., 1996, 54, 11169.

2. G. Kresse and D. Joubert, Phys. Rev. B., 1999, 59, 1758.

3. P. E. Blöchl, Phys. Rev. B., 1994, 50, 17953.

4. J. P. Perdew, K. Burke and M. Ernzerhof, Phys. Rev. Lett., 1996, 77, 3865.

5. A. Alavi, P. Hu, T. Deutsch, P. L. Silvestrelli and J. Hutter, Phys. Rev. Lett., 1998, 80, 3650 .

6. A. Michaelides and P. Hu, J. Am. Chem. Soc., 2001, 123, 4235.

7. Z. P. Liu and P. Hu, J. Am. Chem. Soc., 2003, 125, 1958.

8. X. M. Cao, R. Burch, C. Hardacre and P. Hu, J. Phys. Chem. C, 2011, 115, 19819.

9. Y. Mao, Z. Wang, H.-F. Wang and P. Hu, ACS Catal., 2016, 6, 7882.

10. H. Wang, Y. Guo, G. Lu and P. Hu, J. Chem. Phys., 2009, 130, 224701.

11. J. A. Dumesic, The microkinetics of heterogeneous catalysis, American Chemical Society, Washington, DC, 1993.

12. I. Chorkendorff and J. W. Niemantsve, Concepts of Modern Catalysis and Kinetics, Wiley-VCH, Weinheim, 2003.

13. J. F. Chen, Y. Mao, H. F. Wang and P. Hu, ACS Catal., 2016, 6, 7078.

14. Z. Wang and P. Hu, Phys. Chem. Chem. Phys., 2017, 19, 5063.

15. A. V. Ruban, H. L. Skriver and J. K. Nørskov, Phys. Rev. B., 1999, 59, 15990.

16. A. M. Joshi, M. H. Tucker, W. N. Delgass and K. T. Thomson, J. Chem. Phys., 2006, 125, 194707.

17. H. Liao, A. Fisher and Z. J. Xu, Small, 2015, 11, 3221.

18. M. Gajdoš, J. Hafner and A. Eichler, J. Phys. Condens. Matter, 2006, 18, 13.

19. M. Mavrikakis, J. Rempel, J. Greeley, L. B. Hansen and J. K. Nørskov, J. Chem. Phys., 2002, 117, 6737.

20. X. Q. Gong, R. Raval and P. Hu, Surf. Sci., 2004, 562, 247.

21. T. Li, B. Bhatia and D. S. Sholl, J. Chem. Phys., 2004, 121, 10241. 